\title{
Glotofobia, fenômeno de estigmatização social: entrevista com Philippe Blanchet ${ }^{1}$
}

\section{Shirlei Baptistone ${ }^{2}$}

Resumo: Nesta entrevista, o sociolinguista Philippe Blanchet aborda o tema da discriminação linguística, definida por ele como glotofobia. Blanchet contribuiu enormemente para a conceituação desse fenômeno e vem atuando na luta contra este tipo de segregação social. A presente entrevista foi realizada meses após o término do meu estágio de doutorado sob sua direção, auxiliado pela Professora Gudrun Ledegen, no laboratório PREFICS (Pôle de Recherche Francophonies, Interculturel, Communication, Sociolinguistique), na Université de Rennes 2. Esse estágio foi realizado no âmbito do projeto de internacionalização CAPESPrInt "Multilinguismo, direitos linguísticos e desigualdade social", da Universidade Federal Fluminense.

Palavras-chave: Glotofobia. Língua. Classe social. Segregação social Ideologia.

Em 1998, você cunhou a palavra "glotofobia" para designar discriminação, desprezo, ódio, agressão ou depreciação de pessoas pelo uso de certas formas linguísticas consideradas incorretas, inferiores à língua oficial ou padrão, aquela que recebe prestígio social. Que leitura podemos fazer de um país que se orgulha de ser o país dos direitos humanos, mas que ainda mantém vigorosamente a ideologia da estigmatização social e não reconhece a seriedade de tal discriminação? Lembro-me de um recente caso de discriminação linguística relatado pela mídia, em julho de $2020^{3}$, após a nomeação do novo Primeiro Ministro, Jean Castex, quando algumas

1 Professor Dr. Philippe Blanchet; Universidade de Rennes. Professor de sociolinguística e didática da linguagem, Departamento de Comunicação, Universidade Rennes 2. https://blogs.mediapart.fr/philippe-blanchet/blog

2 Doutoranda em Estudos de Linguagem pela Universidade Federal Fluminense. Professora de francês do Instituto de Aplicação Fernando Rodrigues da Silveira (CAp UERJ).

As perguntas serão antecedidas com as iniciais: PH: iniciais de Philippe Blanchet e SB: iniciais de Shirlei Baptistone.

3 https://france3-regions.francetvinfo.fr/occitanie/haute-garonne/toulouse/glottophobie-nouveau-premierministre-jean-castex-victime-discrimination-raison-son-accent-du-sud-ouest-1850298.html 
pessoas zombaram de seu sotaque.

Como nos lembra Robert Badinter, ex-Ministro da Justiça e membro do Conselho Constitucional francês, a França não é o país dos direitos humanos por duas razões. A primeira delas é que, embora a França seja o país onde a Declaração dos Direitos do Homem e do Cidadão foi proclamada em 1789, ela não é o país onde a própria ideia dos direitos humanos e desse tipo de declaração foi criada. A declaração inicial foi feita um século antes, na Inglaterra (a Bill of Rights, de 1689, cuja origem remonta ao Habeas Corpus de 1215) e foi especialmente incluída nas primeiras dez emendas da primeira Constituição americana elaborada entre 1777 e 1791, que influenciou os revolucionários franceses. A segunda razão é que o Estado francês, sob vários regimes políticos desde 1789, tem desrespeitado regularmente os direitos humanos e continua a fazêlo até hoje, a ponto de ser condenado pela Corte Europeia dos Direitos Humanos e interpelado pela Comissão das Nações Unidas para os Direitos Humanos. A França contribuiu para a afirmação dos direitos humanos, mas daí a afirmar que ela é a origem ou o principal símbolo desses direitos é uma publicidade enganosa, bem afinada com a arrogância francesa, que se apresenta para o mundo como a portadora das luzes e das mensagens universais.

Dessa forma, não é surpreendente que ao longo da história francesa uma outra tendência profunda que se tenha desenvolvido e continue a desenvolver-se: a tendência despótica. A França tem uma tradição contínua de regimes despóticos, desde o século XVII com a monarquia absolutista, passando pelo Período do Terror, em 1793, quando a Revolução se tornou uma ditadura, pelos governos de Napoleão I e Napoleão III, pela colonização, pelo regime de Pétain, durante a Segunda Guerra Mundial, pelos aspectos monárquicos da Quinta República a partir de 1958 e pelas ideias da extrema direita que continuam a circular amplamente até mesmo entre as pessoas da chamada direita "republicana" ou mesmo do "centro" (como o regime macronista, no momento) ou supostamente de "esquerda" (como Manuel Valls). A partir de 1793, essa tendência despótica se uniu 
a uma outra não especificamente francesa, aquela do nacionalismo. Isso deu origem a um nacionalismo despótico de tal forma presente na França que, a partir de 1789, o objetivo passou a ser construir um Estado-nação centralizado e, portanto, uma nação unificada que até então não existia. Assim, a França que conhecemos hoje resultou de uma agregação de regiões e de povos que, inicialmente, eram muito distintos, com histórias, culturas e línguas diferentes, mais ou menos reunidos sob a realeza francesa, com status variados, incluindo até uma autonomia muito forte e o status de uma "província considerada estrangeira" (era o caso, por exemplo, de minha região de origem, a Provença, onde o francês só se generalizou ao longo do século XX).

A grande burguesia e a aristocracia "modernista" tomaram o poder em 1789 e recuperaram os atributos da aristocracia real. Elas escolheram unificar fortemente o país em torno de uma identidade nacional a ser construída, de seu centro parisiense e de um elemento emblemático: a língua francesa, que era então apenas a forma popular da língua da grande área geográfica da bacia de Paris e a língua das classes dirigentes de forma artificialmente reconstruída, latinizada e complexificada. $O$ francês foi então erguido como um totem de identidade nacional, venerado, sacralizado, principalmente na forma padronizada das elites. A partir daí, foi criada uma verdadeira ditadura linguística: imposição do francês, proibição de muitas outras línguas da França, estigmatização das populações (mesmo sendo uma grande maioria) que falavam essas outras línguas. As escolas desempenharam e continuam a desempenhar um papel importante no estabelecimento e na perpetuação da glotofobia estatal, inclusive no plano jurídico, que tem sido inculcada como "normal" e "desejável" ao longo de várias gerações. No final do século XIX, o francês ainda era pouco praticado na França, mas sua posição de prestígio, de dominação e aspiração foi poderosamente estabelecida. Durante o século XX, a população tornouse gradualmente francófona. Entre os anos de 1950 e 1970, as crianças eram educadas em francês (mas não todas). Como resultado, surgiram variedades regionais do francês, influenciadas pela primeira língua local 
dos habitantes, e, particularmente, os famosos sotaques. O Estado passou, então, a persegui-los por intermédio das escolas, da mídia, dos critérios de promoção social e do processo de homogeneização linguística, rejeitando as formas regionais de francês, considerando-as errôneas, estigmatizando e ridicularizando-as em prol de um modelo hegemônico do francês da burguesia parisiense. Essa política linguística foi acompanhada por uma política de educação "patriótica", de ensino nacionalista de uma história reduzida e parcialmente falsificada, da imposição de uma "cultura comum", por exemplo, literária. De minha parte, além do fato de minha língua familiar, o provençal, ter sido totalmente banida da escola (minha avó foi severamente castigada na escola por utilizá-la), nunca me ensinaram nem a história da Provença (há muitos anos independente), nem a rica literatura provençal, por exemplo.

A ideia de que seria "normal" e "justificado" proibir uma pessoa de expressarse em sua primeira língua, além do francês, menosprezar as línguas regionais chamadas patois ou uma forma não padronizada de francês, impor o uso de uma única língua e sua variedade normativa, tudo isso está tão profundamente enraizado na ideologia nacional francesa que a maioria das pessoas nem sequer imagina que ela possa ser discriminatória, injusta, abusiva e muito provavelmente ilegal. A relação com as chamadas "línguas de imigração" continua marcada pelo espírito de superioridade colonial e pela ordem de assimilação. Houve algum progresso nos últimos anos, sobretudo na aceitação dos "sotaques" em francês, daí os casos recentes da mídia que você mencionou. A noção de glotofobia, indispensável para analisar e identificar a discriminação sobre pretextos linguísticos, começou a espalhar-se na França desde a publicação de meu livro de 2016 ${ }^{4}$. Mas isto é apenas o começo, e ainda há profundas mudanças a serem feitas. Como você pode ver, eles abordam questões fundamentais que são difíceis de modificar.

4 BLANCHET, Philippe. Discriminations: combattre la glottophobie. Paris: Textuel, 2016 [coll. Petite Encyclopédie critique]. 
Como a promoção de expressões como língua legítima, língua única, língua da República, domínio do idioma, superioridade de um idioma língua sem sotaque, corresponde a um ideal normativo e contribui para o reforço das representações glotofóbicas?

Toda esta parafernália terminológica, que poderia ser complementada, por exemplo, com "erro linguístico, dialeto, patois" serve para estabelecer na sociedade e na mente das pessoas, por meio da educação escolar, a ideia de que essa visão das línguas, e do francês em particular, faz parte de um sistema completo, lógico, natural e, portanto, poderosamente convincente.

Fale-nos um pouco mais sobre a ideologia linguística francesa que faz da língua não apenas o cimento sagrado da identidade nacional, como também um símbolo de distinção de classe social.

Expliquei aqui a construção linguística de uma identidade nacional francesa assimiladora (porque poderia ser bem diferente: pluralista, federalista, plurilíngue). Mencionei de passagem que, de fato, foi a grande burguesia que se amparou na Revolução Francesa para tomar o poder em lugar da aristocracia (parte da qual adere ao projeto revolucionário por convicção ou oportunismo e permanece no poder). Impor a língua da capital (que permanece Paris), a língua do poder (que permanece central e muito rapidamente se torna extremamente centralizada) significa instalar um filtro muito poderoso no acesso ao poder em uma época em que a grande maioria da população do país (provavelmente mais de $75 \%$ ) não sabe nada de francês, especialmente as camadas populares, os camponeses, os operários, os artesãos, os pequenos comerciantes. Adicionar aí um segundo filtro, o do francês normativo e sua grafia deliberadamente complicada, significa restringir ainda mais a possibilidade de acesso ao poder e aos recursos que ele oferece. Pierre Bourdieu analisou muito bem como, ainda hoje, na França, o "capital simbólico" que constitui a língua serve para distinguir as classes sociais. O sistema escolar francês, um dos mais desiguais do mundo, que aumenta a desigualdade em vez de reduzi-la (apesar de alguns casos de sucesso marginais que servem de 
álibi), é baseado na língua. O legítimo idioma francês, prescrito pela escola e exigido para o sucesso escolar (ligado ao avanço socioeconômico), é claramente o das classes sociais abastadas das grandes cidades da metade norte da França, com base no modelo da burguesia parisiense. Seus efeitos são sentidos em outras esferas de poder: na mídia e na política, das quais são excluídos, exceto em nível muito local, todos aqueles que não adotam essa norma linguística. E não estou nem mesmo falando com você sobre a ideia de usar uma língua que não seja o francês: quando o presidente da coletividade territorial da Córsega, eleito democraticamente com sua maioria autonomista-independentista da Córsega, falou simbolicamente por três minutos em língua corsa em 2015, ele sofreu um verdadeiro linchamento pela mídia e pelos políticos da França continental.

Em sua opinião, existe uma ligação entre o surgimento de normas endógenas e as desigualdades sociais nos países francófonos?

Não, eu acho que não, trata-se de uma norma prescritiva. Os usos e o nível de proficiência em francês são frequentemente um reflexo das desigualdades sociais nos chamados países francófonos do "Sul", pois, mesmo que o francês seja a única língua oficial para a promoção socioeconômica e educacional, ele é principalmente um apanágio das classes sociais abastadas. Mas nestes grupos sociais são feitos esforços para falar o máximo possível de acordo com a norma parisiense, sem nunca conseguir fazê-lo plenamente, uma vez que o biplurilinguismo produz seus efeitos normais de misturas linguísticas, mesmo que apenas em grau limitado. Para que surja uma norma endógena, ela deve ser baseada em práticas que sejam locais e compartilhadas por uma grande parte da população, incluindo as classes dominantes, mas não se limitando a elas. Essa ideia também vale para os chamados países francófonos do "Norte".

Conte-nos um pouco mais sobre o paradoxo que escreveu sobre a língua francesa em um artigo de 2014: "O francês seria (paradoxalmente), internacionalmente, a garantia da diversidade diante de uma suposta 
tendência hegemônica do inglês e, na França, a garantia da unidade (outro paradoxo) diante de uma suposta tendência comunitária das chamadas línguas regionais e da imigração $0^{5 "}$.

Gostaria de salientar que o discurso do Estado francês é exatamente o oposto, dependendo se ele fala do internacional ou do nacional. Internacionalmente, ele apoia a diversidade linguística e o plurilinguismo, provavelmente por interesse: o francês contra seu rival número um, o inglês, que corre o risco de tornar-se a única língua internacional; o francês com as chamadas línguas nacionais e locais em países francófonos a fim de melhor ser aceito nesses lugares. Na França, por outro lado, o discurso é reduzir ao máximo a diversidade linguística, como já disse anteriormente.

A política de homogeneização linguística é comum às línguas e às culturas do mundo, mesmo que a diversidade linguística e cultural seja uma realidade? Por que é assim?

Não. Há muitas sociedades, muitos Estados, que organizam a diversidade linguística e cultural. Eles não procuram reduzi-la ou destruí-la, mas, ao contrário, desenvolvê-la. Eles têm vários idiomas oficiais e reconhecem os direitos linguísticos. Tomemos como exemplos: o Mali, a Bolívia e as ilhas Maurício, mas também, em diferentes graus, a África do Sul, a Espanha, o Marrocos, o Reino Unido, o Senegal e a Suíça não faltam exemplos. Mas há também uma tendência, inerente à noção de Estado-nação, correlacionada com poderes autoritários, ideologias nacionalistas e até xenófobas, para tentar impor o monolinguismo e erradicar o plurilinguismo: a França, a Espanha sob Franco, a Itália sob Mussolini, a Turquia, a URSS sob Stalin.

Você concorda que, de acordo com as práticas dos atores glotopolíticos (linguistas, instituições, cidadãos), eles podem desempenhar o papel de agentes glotofóbicos?

5 BLANCHET, Philippe; CLERC, Stephanie; RISPAIL, Marielle. Réduire l'insécurité linguistique des élèves par une transposition didactique de la pluralité sociolinguistique. Pour de nouvelles perspectives sociodidactiques avec l'exemple du Maghreb. Éla: Études de linguistique appliquée, v. 3, n. 175, 2014. 
Sim, eu concordo plenamente. Cada pessoa é um agente glotopolítico que contribui de sua própria maneira para estabelecer, confirmar, reforçar ou desafiar, subverter, transformar, substituir uma ordem sociolinguística. Isso acontece mesmo em seus comportamentos linguísticos mais «micro», como ao corrigir uma criança para que fale de uma determinada forma, em uma determinada situação, ou até mesmo ao desdenhar uma pessoa porque ela fala de certa maneira, tem um sotaque, usa uma determinada palavra ou língua. Ou, ao contrário, para encorajar as pessoas a falarem de uma certa maneira, a aprender um idioma etc.

O ano de 2020 foi abalado pelo assassinato do americano George Floyd e pelas manifestações antirracistas ao redor do mundo. Será finalmente uma oportunidade de dar voz a tantos outros grupos minoritários? O que pensa sobre isso?

PB: É uma luta muito antiga, muito longa e muito difícil. Por um lado, porque os sistemas de dominação e desigualdade estão embutidos nas próprias estruturas das sociedades (e, portanto, difíceis de mudar). Por outro lado, porque essas dominações foram transformadas em hegemonia, o que faz com que os dominados as aceitem, acreditem que são inevitáveis ou mesmo normais, e, às vezes, até contribuam para elas. Finalmente, porque as "maiorias" (não em número, mas em poder), que se beneficiam do sistema, são ambas muito poderosas e muito espertas: elas dividem as "minorias" (não em número, mas em poder) entre si para evitar que se unam e lutem juntas contra o próprio princípio de dominação e desigualdade. Eles colocam os pobres daqui contra os pobres de outros lugares, negros contra ameríndios ou imigrantes recentes; eles criam uma espécie de hierarquia de dominação e discriminação para que aqueles que se sentem mais discriminados do que outros reivindiquem prioridade sobre os outros. Entretanto, todas as discriminações têm o mesmo processo e o mesmo resultado. Quer seja por um pretexto glotofóbico ou xenófobo ou homofóbico ou racial, no final, há sempre uma pessoa privada de seus direitos. 
Em sua opinião, como a universidade pode desempenhar um papel na luta contra a glotofobia?

Por intermédio da educação, essa é uma de suas missões. Também por meio da pesquisa e, finalmente, não praticando a própria glotofobia, desenvolvendo, ao contrário, o acesso ao plurilinguismo e, em particular, às línguas minoritárias.

Muito obrigada, Professor Blanchet, por sua participação neste número do Cadernos de Letras da UFF dedicado ao tema "Multilinguismo, Discurso e Direitos Linguísticos”.

Glottophobia, a phenomenon of social stigmatization: interview with Philippe Blanchet

Abstract: In this interview, sociolinguist Philippe Blanchet addresses the topic of linguistic discrimination, defined by him as glotophobia. Blanchet has contributed enormously to the conceptualization of this phenomenon and has been active in the fight against this type of social segregation. The present interview was conducted months after the end of my doctoral internship under his direction, assisted by Professor Gudrun Ledegen, at the PREFICS laboratory (Pôle de Recherche Francophonies, Interculturel, Communication, Sociolinguistique), at the Université de Rennes 2. This internship was carried out within the framework of the CAPES-PrInt internationalization project "Multilingualism, linguistic rights and social inequality", at the Universidade Federal Fluminense.

Keywords: Glottophobia. Language. Social class. Social segregation. Ideology.

Recebido em: 01/12/2020

Aceito em: 13/04/2021 


\section{Dossiê}

Multilinguismo, discurso e direitos linguísticos 